\title{
PARAPLEGIA
}

\section{Index to volume I6 (1978/79)}

\section{Subject index}

\author{
Ambulation \\ Ambulation without wheelchairs for para- \\ plegics with complete lesions, by $\mathrm{H}$. Natvig \\ and R. McAdam I 42
}

Beds

Simpson-Edinburgh low pressure air bed: an early clinical evaluation, by E. McClemont et al. I54

\section{Biochemistry \\ Hypercalcaemia in adolescent tetraplegic patients: case report and review, by F. U. Steinberg et al. 60}

\section{Cervical spine fractures}

Fracture dislocation of the cervical spine: a critique of current management in the United States, by B. J. Sussmann Is

\section{Contrast reactions}

Are spinal cord injured patients more prone to contrast reactions? by A. T. Scher 366

\section{Epidemiology}

Epidemiology of spinal cord injury in the Rhône-Alpes region, France, 1970-75, by P. Minaire et al. 76

\section{Ergonomics}

An ergonomic appraisal of the use and functional efficiency of condom urinals in the male patient with spinal cord paralysis, by S. D. Lawson and J. B. Cook 3I7

\section{Foreign body}

Localisation of upper oesophageal foreign bodies in a recumbent tetraplegic patient, by A. T. Scher 295

\section{Hypertension}

Pentolinium for control of reflex hypertension in spinal cord injured patients, by S. Muravchick et al. 350

\section{Microbiology}

The role of the microbiologist in the treatment and rehabilitation of patients with spinal cord injuries, by R. Linden 237

\section{Neurological recovery}

Neurological recovery distal to the zone of injury in 172 cases of closed traumatic spinal cord injury, by J. S. Young and W. R. Dexter 39

\section{Neuro-pathology}

Actual concept of osteoporosis in paraplegia, by A. Chantraine $5 \mathrm{I}$

Myelopathy associated with systemic Lupus erythematosus (Erythema nodosum) L. S. Kewalramani et al. 282

Myelopathy in cirrhosis, by C. E. Robinson and A. Anzarut 3

Ulnar compression neuropathy: an uncommon complication in surgical repair of pressure ulcers, by M. Nath and R. G. Taylor 370

\section{Nursing}

An evaluation of residential care for tetraplegics, by B. Richards 194

Nursing management in relation to beds used within the National Spinal Injuries Centre for the prevention of pressure sores, by E. C. Rogers I 47

\section{Para-articular ossifications}

The para-articular ossifications in our paraplegics and tetraplegics: a survey of 704 patients, by A. M. Hernandez et al. 272

\section{Paraplegia}

Factors influencing readmission to hospital: II. Paraplegia, by I. G. Burnside and J. B. Cook 276

\section{Physiology}

Electrical splinting of the knee in paraplegia, by G. S. Brindley et al. 428

\section{Physiotherapy}

An exercise test to evaluate fitness for wheelchair activity, by R. M. Glaser et al. 34I 


\section{Pressure sores}

Pressure redistribution in wheelchair cushion for paraplegics: its application and evaluation, by A. G. Key et al. 403

The function of the rump in relation to sitting and the Keane Reciprocating Wheelchair Seat, by F. X. Keane 390

The minimum physiological mobility requirement for man supported on a soft surface, by F. X. Keane 383

The polystyrene vacuum wheelchair cushion, by $\mathrm{H}$. W. F. Jones and Miss A. Evans 420

Using warning devices to improve pressure relief training, by J. C. Chawla et al. 4I3

\section{Psychology}

Importance of communication in counselling the spinal cord injury patient, by V. M. Santana Carlos 206

Past history and degree of depression in paraplegic individuals, by V. Katz et al. 8

Physiotherapeutical mistakes in the early stages after spinal cord injury, by $\mathrm{A}$. Th. Terbizan 233

The high-level tetraplegic: psychological survival and adjustment, by L. Burnham and G. Werner I 84

The role of the psychologist in the treatment of spinal cord injury, by R.B.Trieschmann 2 I2

\section{Rehabilitation}

Cooperation between physicians and advisory services in a vocational rehabilitation centre, by T. Huber 220

Shoulder complcations as a cause of delay in rehabilitation of spinal cord injured patients (case reports and review of the literature), by A. Ohry et al. 3 Io

\section{Respiration}

Mobility and equipment for the ventilatordependent tetraplegic, by L. M. Dingemans and J. M. Hawn I75

The use of operant conditioning techniques in the respiratory rehabilitation of the tetraplegic, by D. J. E. Cheshire and W. J. Flack I62

\section{Sexual promotion}

Electro-ejaculation of a complete paraplegic followed by pregnancy, by N. Francois et al. 248

Social work

Some reflections of a medical social worker in a spinal paralysis unit, by $M$. A. Thompson 202

Spinal injuries

Injuries to the cervical spine sustained while carrying loads on the head, by A. T. Scher 94

Pes cavus and claw toes deformity in patients with spinal cord injury and multiple sclerosis, by $M$. Rivera-Dominguez et al. 375
Spinal cord injuries as a result of motorcycle accidents, by R. D. Shrosbree IO2

Spinal injuries in Rangoon, Burma, by T. Toe I 8

Three unusual cases of spinal cord injury in childhood, by M. Renard et al. I30

Traumatic rupture of the aorta and paraplegia, by R. Gschaedler et al. I23

\section{Sport}

A new flexible spring-coil multi-directional mounting device (with proposal of rules) for target shooting by the disabled, by A. Ohry and E. Talmor 5

\section{Statistical survey}

Incidence of traumatic paraplegia and tetraplegia in Norway: a statistical survey of the years 1974 and 1975, by R. Gjone and L. Nordlie 88

\section{Thrombosis}

Anti-coagulant therapy in the prevention of venous thrombosis and pulmonary embolism in the spinal cord injury, by $\mathrm{N}$. Watson 265

Experience with the management of thromboembolism in patients with spinal cord injury: Part I. Incidence, diagnosis and role of some risk factors, by A. Perkash $e t$ al. $\quad 322$

Prevention of thrombophlebitis in spinal injury patients, by E. van Hove 332

\section{Transverse myelitis}

Tropical paraplegia: a case of transverse myelitis, probably caused by Schistosomiasis mansoni, by G. M. Pool II3

\section{Urinary tract}

Anal and urethral sphincter electromyography in spinal cord injured patients, by R. Girard et al. 244

A relationship between the composition of the urine and that of urinary tract calculi in spinal patients, by R. G. Burr 68

Our surgical approach towards the treatment of urethrocele and urethral fistula, by $\mathrm{F}$. Jurascheck et al. 252

Transurethral external sphincterotomy sans external sphincter, by M. S. Rao et al. 306

Two technical aids for intermittent sterile catheterisation, by D. M. Boles 303

Urihesive: a new aid in the management of urinary incontinence in male paraplegic patients, by J. de Leval and J. C. Louis 299

Urolithiasis in children with spinal cord injury, by J. A. Tori and L. S. Kewalramani 357

When is an ileal conduit indicated in the spinal cord patient? by R. H. Hackler 257 